\title{
Conceptual Understanding and Interest in Kinematics among Senior High School Students of MSU-Saguiaran in a Cooperative Learning Environment
}

\author{
MonarizaBacaro \\ Mindanao State University \\ Main Campus, Marawi City, Philippines
}

\begin{abstract}
This study was conducted to determine the level of conceptual understanding and interest in Kinematics of 66 nonscience curriculum high school students under a cooperative learning environment randomly assigned to the control (Traditional Method of Teaching) and experimental group (Cooperative Learning Approach). Student's level of conceptual understanding was measured using a SOLO level-based Conceptual Understanding Test (CUT) and interest in kinematics was measured using a Student's Interest in Kinematics Questionnaire. Before intervention, findings revealed that almost all of them could not answer questions that require one piece or more than one piece of given information, fact, or idea, obtained directly from the problem or ideas each used separately. They could not also answer two or more distinct steps, with no integration of the ideas or in doing algorithms with numbers using a set of useful information. Majority of them were on the prestructural and same level of conceptual understanding and has not really understand the concept asked, or with very little understanding, but they differ on interest level in learning kinematics in favour to the students assigned in the control group. After intervention, students exposed to Cooperative Learning Approach have significantly higher Pretest-Posttest mean gain score in the CUT than the students exposed to Traditional Learning Method. Almost half of the respondents were on the unistructural and less than one fourth were on the multistructural SOLO levels of conceptual understanding. However, students exposed to traditional method of teaching have interest that is significantly higher than the students exposed to cooperative learning approach. In terms of students performance students exposed to cooperative learning approach performed significantly higher than the students exposed to traditional teaching methods.
\end{abstract}

Keywords: conceptual understanding, interest, kinematics, traditional learning method, cooperative learning approach.

\section{INTRODUCTION}

Worldwide findings claimed that physics students at all levels show poor conceptual understanding of the basic concepts and principles in Physics (MCKittrick and Mulhall, 2001). Many students acquire knowledge of the correct algorithm to handle traditional assessment questions but have difficulty applying their knowledge to related but unfamiliar situations due to lack of understanding of the basic underlying concepts. Mazur (2015) reported that students in his physics class had memorized equations related to problem solving, but performed poorly on tests of conceptual understanding. Nakhleh and Mitchell (1993) also revealed that from sixty students in an introductory course in physics for chemistry majors, only $49 \%$ of those students had high algorithmic ability and were able to answer parallel conceptual questions. From all these studies, it shows that students leave with the impression that physics is an incomprehensive hash of arbitrary assertions.

All too often physics has the reputation of being the "most difficult" or "killer" subject that the less fortunate students would normally fail in the course. The belief that physics is nothing but mathematics and equations and the emphasis that many teachers and student place on "using the suitable equation" has all but do away with thoughts and conceptual understanding among students. While, it is true that physics requires more effort 
and out-of-class study time than some other disciplines, it is also true that in most part of the concepts of physics it is much more straightforward and understandable than most-scientist realize.

The emphasis in many physics subject classes is on problem solving. These normaly imprints on the student's mind that physics is merely remembering the technique for solving particular types of problem or memorizing formulas aided and abetted by instructors solving numerical problems in class or setting them as homework. Often these problems are highly contrived with little connection with real-life situation. In this context, the role of equation is a commonplace in the physics although, perhaps, some mathematical manipulation may be necessary. As a result, in most physics classes, conceptual understanding takes a back seat to problem solving techniques and mathematical ability. This is not to say that equations have no place in a conceptual approach; they should not be used however, for simply plugging numbers or substituting what the equations require but as a guide to thinking and understanding. With these, physics appears to students as very abstract and mathematical in nature. Consequently, they may have difficulty in absorbing the concepts being taught and that they perceive the workload and speed of progression in physics courses as complex, resulting to their low grades. Looking on how the teachers deal with these problems is not obvious. Since effective learning is the primary goal of teaching and learning processes, the student understands of concepts and principles should be given more priority. A prerequisite for effective learning or understanding should be to get the students interest in the subject. The concept of a "difficult subject" has been perceived by them and as a cause their lack of interest in physics. The hope of helping students become more active and intellectually engaged learners by exposing them to various strategies and learning environment is the subject of interest in this study. One such strategy is cooperative learning.

Studies showed that cooperative learning has many positive outcomes. It improves student's efforts to achieve. They work harder, achievement levels go up, material is remembered longer, higher-level reasoning is used more, and it provides not just external motivation but also intrinsic motivation.Furthermore, complex learning tasks such as problem solving, critical thinking and conceptual learning improve noticeably when cooperative strategies are used (Lundgren, 1994). All of the positive effects that cooperation has on so many important outcomes make cooperative learning one of the most valuable tools educators have.

According to Gericke (2015), in education, learners are supposed to grow in competence as they learn. It is not sufficient that learners only accumulate knowledge. What should be focused on is the student's performance in the aspect of understanding knowledge. Such understanding will cause students to act differently in contexts involving the content that has been understood. This further emphasizes that those internally involved in the classroom, that is, teachers and students, should be greatly involved in assessing the learning process. This will require a radical change in the methodologies or strategies as well as course material such as cooperative learning approach in education.

Learning physics without understanding the central concepts is like a half-cooked food or a wanderer who does not know his destination. Because of this, the study was conducted to provide educators with baseline information on the effectiveness of cooperative learning as an instructional approach in raising conceptual understanding and interest in kinematics. Hopefully, this will serve as a guide for their future plans in strengthening physics programs in their schools. Furthermore, the result of this study in envisioned to encourage physics teachers to explore various teaching strategies that will effectively increase the interest of students and improve their conceptual understanding of physics concepts.

The findings of this study may also give the school administrators, physics teachers and even the curriculum designers and researchers baseline information regarding the level of conceptual understanding of nonscience curriculum high school students in physics. It is hoped that teachers may exert effort to teach physics giving more emphasis to concepts and principles. In this manner, the student's understanding of concepts in physics will be enhanced.

\section{Participants}

\section{METHOD}

The sample of the study consisted of all the sixty six (66) fourth year non-science high school students of MSUSaguiaran Community College, Saguiaran, Lanaodel Sur. There were two group samples; grouping was done by 
random assignment of the students from section A and B to comprise the control and experimental groups. Each group consisted of 33 students. Assigning the Control Group and the Experimental Group was done by tossing of coins. The age of the samples range from fifteen to eighteen years with a mean age of 16.87 . There were fourty six (46) female and twenty (20) male respondents. All of them were Maranao.

\section{Design}

The researcher adopted the experimental method of research. The experiment was done to determine the level of conceptual understanding and interest of non-science curriculum high school students in Kinematics using Cooperative Learning Environment Approach as compared to students who were exposed to Traditional Learning Method.

\section{Materials:}

The principal research instruments used in this study were the Conceptual Understanding Test (CUT) and the survey questionnaire on the interest of students in Kinematics.

\section{Procedure:}

A letter was sent to the Principal of MSU-Saguiaran Community College informing her of the intention, purpose and the nature of the study and requesting for her permission and approval to conduct the study in the school. After the permission was granted, a pretest of the Conceptual Understanding Test (CUT) was administered to the two groups to determine the initial comparability of the students' conceptual understanding on Kinematics. The pretest of the students' interest in Kinematics questionnaire was administered.

The intervention was done within two weeks. The two groups of sampled students were taught the topics on "Kinematics". The Control Group was taught using the traditional method of instruction, which included oral reading of textbook, classroomdiscussion, overhead notes, chapter outlines and oral reviews at the same time, the students read the assigned reading materials silently and complete worksheets independently on their seats, in short the chalk and board lecture discussion style. The students in the Experimental Group on the other hand were taught by cooperative learning approach. They were divided into cooperative groups of six, and each group has five to six members. After the grouping, they were informed that the performance of each member is dependent upon the performance of the group; each member is accountable not only for his performance but is also accountable for the performance of the whole group. A team leader has been chosen by each group and is responsible for dividing and assigning the tasks to each member.

The students or the members in each group were encouraged to interact, share knowledge and discuss together the assigned topic, questions or problems for twenty five minutes until each member had already mastered, understood and absorbed the concept about the subject matter. After the time frame set for discussion and exchanging ideas together and working together on a problem is up, a test or assessment, either in written or oral form followed. That is, everybody joined in a question and answer session. Each member is given numbers of 1, 2, $3,4,5$, and 6 . The teacher calls out a number, let say one from group three, then student with number one from group three gave the answer to the question raised by the teacher about the topic.

The time schedule of classes for the Experimental Group was every first period; 7:30 to 8:30 in the morning daily while for the Control Group was every second period, 8:30 to 9:30 in the morning. To ensure unbiased treatment by the researcher, the teacher-in-charge of the two classes was requested to observe throughout the duration of the experiment to see to it that the researcher did not deviate from the lesson plans.

A Posttest on the Conceptual Understanding Test (CUT) was given to the study samples after the end of intervention to measure their conceptual understanding. The test papers from both groups of the said test were checked using rubrics (scoring scheme). Student's individual scores served as the measurement for their individual conceptual understanding in Kinematics. The pretest-posttest mean scores of the two groups in the CUT were computed and were the basis of comparison of their conceptual understanding. 
A survey questionnaire on the interest and the level of interests of students in physics was administered. This was followed by an interview to determine consistency of responses obtained from the survey questionnaire. Ten students were randomly chosen for the interview. The results were tabulated, analyzed and interpreted.

\section{Student's Level of Conceptual Understanding}

\section{RESULTS}

The level of conceptual understanding of the students respondents in the treatment and control groups were determined using the mean percentage distribution of the students who answered correctly the questions classified under SOLO Classification for each of the Kinematics problems.

\section{A. Before the Intervention}

Analysis of the answers of the students in the Conceptual Understanding Test (CUT) showed that majority of them $(81.255 \%)$ were on the prestructural level in the conceptual understanding test before the intervention. This means that the task was not done appropriately and perhaps the students have not really understood the concept. It also indicates that no understanding was demonstrated. At the pre-structural level the students did not learn the concepts. Table 1 shows the percentage distribution and mean percentages of the students who answered correctly the four questions in the first two-SOLO levels. Twelve problems were administered. Each problem had two unistructural level questions and two multistructural level questions.

Table1

Mean Percentage Distribution of Students with Correct Answers for Each SOLO Level in the Twelve Problems of the Conceptual Understanding Test Pretest

\begin{tabular}{|c|c|c|c|c|c|c|c|c|c|c|c|c|c|c|c|}
\hline \multirow[t]{2}{*}{ GROUP } & \multirow[t]{2}{*}{$\mathbf{N}$} & \multirow{2}{*}{$\begin{array}{l}\text { SOLO } \\
\text { LEVEL }\end{array}$} & \multicolumn{12}{|c|}{ PROBLEMS } & \multirow{2}{*}{$\begin{array}{c}\text { GRAND } \\
\text { MEAN } \\
\%\end{array}$} \\
\hline & & & 1 & 2 & 3 & 4 & 5 & 6 & 7 & 8 & 9 & 10 & 11 & 12 & \\
\hline \multirow{6}{*}{$\begin{array}{l}\text { CONTROL } \\
\text { GROUP }\end{array}$} & \multirow{6}{*}{33} & Unistructural & 33.33 & 18.18 & 57.58 & 6.06 & 12.12 & 15.15 & 6,06 & 9.09 & 0 & 0 & 3.03 & 9.09 & 14.14 \\
\hline & & Unistructural & 45.45 & 9.09 & 39.39 & 0 & 0 & 3.03 & 0 & 33.33 & 0 & 0 & 0 & 9.09 & 11.62 \\
\hline & & MEAN $\%$ & 39.39 & 13.64 & 48.48 & 3.03 & 6.06 & 9.09 & 3.03 & 21.21 & 0 & 0 & 1.52 & 9.09 & 12.88 \\
\hline & & Multistructural & 6.06 & 0 & 6.06 & 0 & 0 & 0 & 0 & 6.06 & 0 & 3.03 & 0 & 0 & 1.77 \\
\hline & & Multistructural & 30.3 & 3.03 & 0 & 0 & 0 & 3.03 & 3.03 & 21.21 & 6.06 & 3.03 & 0 & 3.03 & 6.06 \\
\hline & & MEAN \% & 18,18 & 1.51 & 3.03 & 0 & 0 & 1.51 & 1.51 & 13.64 & 3,03 & 3.03 & 0 & 1.51 & 3.91 \\
\hline \multirow{6}{*}{$\begin{array}{l}\text { EXPERIMENTAL } \\
\text { GROUP }\end{array}$} & \multirow{6}{*}{33} & Unistructural & 27.27 & 48.48 & 4848 & 21.21 & 6.06 & 48.49 & 3.03 & 27.27 & 6,06 & 3,03 & 606 & 3.03 & 20.71 \\
\hline & & Unistructural & 39.39 & 18.18 & 39.39 & 0 & 15.15 & 9.09 & 9.09 & 33,33 & 3.03 & 0 & 0 & 0 & 13,89 \\
\hline & & MEAN \% & 33.33 & 33.33 & 43.94 & 10.61 & 10.61 & 28.79 & 6.06 & 30.30 & 4.55 & 1.52 & 3,03 & 1.52 & 17.29 \\
\hline & & Multistructural & 6061 & 0 & 0 & 6.061 & 3.03 & 3.03 & 0 & 909 & 0 & 0 & 3.03 & 0 & 2.53 \\
\hline & & Multistructural & 15.15 & 3,03 & 0 & 0 & 0 & 3.03 & 6.06 & 18.18 & 3.03 & 0 & 0 & 3.03 & 4.29 \\
\hline & & MEAN $\%$ & 10.61 & 1.515 & 0 & 3.03 & 1.52 & 3.03 & 3.03 & 13.64 & 1.52 & 0 & 1.52 & 1.52 & 3.41 \\
\hline
\end{tabular}

Table 1 presents the mean percent frequency distribution of the student respondents who got the correct answers in the CUT. Scrutiny of the grand mean percentage further shows that for the unistructural level questions, only $12.88 \%$ among the students in the control group were able to answer the questions correctly. Besides, only $3.91 \%$ of them were able to tackle correctly the multistructural level questions. In the experimental group, the grand mean percentage of respondents who answered correctly the unistructural level questions was a little higher (17.29\%) as compared to the control group. The grand mean percentage of the experimental group of respondents who got correctly the answers to the multistructural level questions was almost the same as the control group (3.41\%, a little lower than the control group).

Poor conceptual understanding of the students may explain the very low mean percentage of the respondents who correctly answered each level of questions as shown in Table 1 . Perhaps this is brought about by the student's lack of knowledge of the concepts and principles in the topics of kinematics. For those who have read the topic in advance, the problem may not appear as difficult to understand instead the questions may seem easier to 
International Journal of Science and Management Studies (IJSMS)

Volume: 2 Issue: 3
May to June 2019
E-ISSN: 2581-5946

www.ijsmsjournal.org

answer. For those who lacked the knowledge of or incorrect understanding of the concept needed to answer the question, an easy problem will always appear a difficult one. These two findings are supported by the result of an earlier study conducted by Cagas (1998) on the investigation of the effectiveness of concept-oriented problemsolving approach to the conceptual understanding in physics. In the study, where the study samples were high school students of science curriculum, it was found out that majority of the high school students were on the first twoSOLO levels of understanding, the unistructural and multistructural level.

To support this contention, Brown (2002) claimed that most secondary school level students took a surface approach (the unistructural and multistructural levels) to understanding both how and what they learn. He found further that majority of Year 11 students defined studying or learning with surface strategies or method (like revision, re-reading, and reviewing) and strongly agreed that learning involved building up knowledge by getting facts and information.

\section{B. After the Intervention}

The mean percentage distribution of the student respondents with correct answer to the SOLO-CUT Posttest is presented in Table 2. It shows the mean percentage of student respondents with correct answers in the unistructural and multistructural level questions for each problem item in the posttest. It is interesting to note that although there was increase in the mean percentage of student respondents in both groups who were able to answer correctly the questions asked under each problem, the increase is not very remarkable. There was also a decrease of the mean percentage in some individual problems and in some cases, the number of students who were able to work on the problems correctly and arrived at correct answers did not change. For example, in the first unistructural questions for problem no. 3, there were $57.8 \%$ of the students in the control group who got the correct answer during the pretest, however, in the posttest, for the same problem and item, this percentage decreased to $48.48 \%$

In the experimental group, except for two multistructural items asked in problem 9 and 12 , there was an increase in the mean percentage of the students who were able to answer both the unistructural and multistructural level questions. On the other hand, 10 questions at the multistructural level were not answered correctly by the student respondents in the control group.

Table 2

Mean Percentage Distribution of Students with Correet Answers for Each SOLO Level in the Twelve Problems of the Conceptual Understanding Test (Posttest)

\begin{tabular}{|c|c|c|c|c|c|c|c|c|c|c|c|c|c|c|c|}
\hline \multirow[t]{2}{*}{ GROUP } & \multirow[t]{2}{*}{$\mathrm{N}$} & \multirow{2}{*}{$\begin{array}{l}\text { SOLO } \\
\text { LEVEL }\end{array}$} & \multicolumn{12}{|c|}{ PROBLEMS } & \multirow{2}{*}{$\begin{array}{c}\text { GRAND } \\
\text { MEAN } \\
\% \\
\end{array}$} \\
\hline & & & 1 & 2 & 3 & 4 & 5 & 6 & 7 & 8 & 9 & 10 & 11 & 12 & \\
\hline \multirow{6}{*}{$\begin{array}{l}\text { CONTROL } \\
\text { GROUP }\end{array}$} & \multirow{6}{*}{33} & Unistructural & 54.55 & 57.58 & 48.48 & 48.48 & 69.69 & 51.52 & 21.21 & 21,21 & 27.27 & 12.12 & 39.39 & 39.39 & 40.91 \\
\hline & & Unistructural & 36.36 & 54.55 & 51.52 & 9.091 & 30.30 & 15.15 & 30.3 & 60.61 & 0 & 12.12 & 27.27 & 30,3 & 29.78 \\
\hline & & MEAN \% & 45.45 & 56.06 & 50 & 28.79 & 50 & 33.33 & 25.76 & 40.91 & 13.64 & 12.12 & 33.33 & 34.85 & 35.35 \\
\hline & & Multistructural & 21.21 & 0 & 0 & 6.061 & 9.09 & 0 & 0 & 9.091 & 0 & 3.03 & 24.24 & 0 & 6.06 \\
\hline & & Multistructural & 48.48 & 6.061 & 6.061 & 0 & 0 & 0 & 27.27 & 39.39 & 0 & 3.03 & 0 & 6.061 & 11.36 \\
\hline & & MEAN \% & 34.85 & 3.03 & 3.03 & 3.03 & 4.55 & 0 & 13.64 & 24.24 & 0 & 3,03 & 12.12 & 3,03 & 8.71 \\
\hline \multirow{6}{*}{$\begin{array}{l}\text { EXPERIMENTAL } \\
\text { GROUP }\end{array}$} & \multirow{6}{*}{33} & Unistructural & 72.73 & 84.85 & 63.64 & 63.64 & 69.69 & 51.52 & 36.36 & 45.45 & 30.30 & 30.30 & 30.30 & 33.33 & 51.01 \\
\hline & & Unistructural & 57.58 & 69.7 & 60.61 & 18.18 & 48.49 & 27.27 & 45,45 & 72.73 & 6,06 & 12.12 & 30.30 & 30.3 & 39.89 \\
\hline & & MEAN \% & 65.15 & 77.27 & 62.12 & 40,91 & 59.09 & 39.39 & 40.91 & 59.09 & 18.18 & 21.21 & 30,30 & 31.82 & 45.45 \\
\hline & & Multistructural & 63.64 & 3.03 & 9.091 & 33.33 & 21.21 & 27.27 & 15.15 & 24.24 & 0 & 18.18 & 24.24 & 0 & 19.95 \\
\hline & & Multistructural & 69.7 & 21.21 & 12.12 & 9.091 & 12.12 & 18.18 & 36,36 & 60.61 & 9.09 & 18.18 & 9.09 & 12.12 & 23.99 \\
\hline & & MEAN \% & 66.67 & 12.12 & 10.61 & 21.21 & 16.67 & 22.73 & 25.76 & 42.42 & 4.55 & 18.18 & 16.67 & 6.061 & 21.97 \\
\hline
\end{tabular}


Table 3 shows the summary of the percentage of students who correctly answered the four questions under the first two-SOLO levels, two unistructural questions and two multistructural questions in both pretest and posttest of the conceptual understanding test (CUT).

Table 3

Summary of Mean Percentage Distribution of Students with Correct Answers for Each SOLO Level in the Twelve Problems of the Conceptual Understanding Test (Pretest and Posttest)

\begin{tabular}{|c|c|c|c|c|}
\hline GROUP & $\mathrm{N}$ & SOLO LEVEL & $\begin{array}{l}\text { PRETEST MEAN } \\
\text { PERCENTAGE }\end{array}$ & $\begin{array}{c}\text { POSTTEST MEAN } \\
\text { PERCENTAGE }\end{array}$ \\
\hline \multirow{6}{*}{$\begin{array}{l}\text { CONTROL } \\
\text { GROUP }\end{array}$} & \multirow[t]{6}{*}{33} & Unistructural & 14.14 & 40.91 \\
\hline & & Unistructural & 11.62 & 29.78 \\
\hline & & MEAN \% & 12.88 & 35.35 \\
\hline & & Multistructural & 1.77 & 6.06 \\
\hline & & Multistructural & 6.06 & 11.36 \\
\hline & & MEAN \% & 3.91 & 8.71 \\
\hline \multirow{6}{*}{$\begin{array}{l}\text { EXPERIMENTAL } \\
\text { GROUP }\end{array}$} & \multirow[t]{6}{*}{33} & Unistructural & 20.71 & 51.01 \\
\hline & & Unistructural & 13.89 & 39.89 \\
\hline & & MEAN \% & 17.29 & 45.45 \\
\hline & & Multistructural & 2.53 & 19.95 \\
\hline & & Multistructural & 4.29 & 23.99 \\
\hline & & MEAN \% & 3.41 & 21.97 \\
\hline
\end{tabular}

Although the two groups, the Control Group and the Experimental Group, showed an increase in their mean percentages, it was the Experimental Group which showed a higher mean percentage increase than the Control Group in each SOLO level. Furthermore, both groups showed the same pattern of the mean percentage distribution of the respondents who correctly answered each level of questions in the Conceptual Understanding Test (CUT). In the ranking of the two levels of questions in terms of the mean percentage of the respondents who correctly answered each level question in the CUT from highest to lowest, unistructural level ranks number one (1) and multistructural level ranks number two (2). This ranking pattern is the same for both the control group and experimental group. The results imply that the multistructural form of questions are difficult for the students to answer and indicates the level of conceptual understanding of the students. It is to be noted that the questions under this SOLO level is comprised of the "why" and the "how" questions which call for explanation, reasoning or solution to numerical problems. The fact that less than $50 \%$ of the students in both groups were not able to answer correctly the questions or apply correctly the formulas and principles means that the students are not ready for these kinds of tasks. Moreover, perhaps they lack the prerequisite knowledge necessary to get the correct answer.

The probable reason why the experimental group showed a higher mean percentage increase in answering correctly the questions in the CUT than the Control Group in the two SOLO levels was that the high school students who were exposed to Cooperative Learning Approach were highly motivated to learn. This is evidences by the t-test result of the Pre-Post Intervention Mean Gain Scores in the Scaled Responses on the Student's Interest in Kinematics Questionnaire of the Experimental Group. A Biggs and Collis (1982) said "the quality of learning not only depends on the quality of instruction but also on the student's motivation, developmental stage, and prior knowledge". If students have no prior knowledge of the content, perhaps due to lack of concentration, and absence of motivation, they cannot respond to the questions.

Likewise, often teachers do not anticipate many of the conceptual difficulties that the students experienced and assumed that the concepts were readily understood. In general, teachers spend little time discussing with students the basic concepts and principles underlying the subject. Usually teachers assume that the prior concepts are well grounded in the minds of the students inasmuch as these were taken in the prerequisite and related subjects. This probably contributed to the student's poor grasp of concepts. Moreover, teachers are resistant to explore some 
or new strategies of teaching that promote students - teachers, student - student and student - materials interaction in the classroom.

Based on the mean percentages presented in Table 3 , about $65 \%$ of the respondents in the control group and $55 \%$ of those in the experimental group were in the prestructural level of the SOLO taxonomy after the intervention. These groups were unable to do the tasks calling for the use of only one piece of information and do not require establishing the relationship of the answer to a question with other ideas.

\section{Conceptual Understanding of the Students in Kinematics}

To determine if there were significant differences in the student's conceptual understanding after the treatment was given, the pretest-posttest mean gain scores of the two groups in the CUT were compared using the ttest for independent samples. Tables 7 and 8 present the results of the analysis performed.

Table 4

Pretest-Posttest Mean Gain Scores in the Conceptual Understanding Test (CUT) of the Two Groups

\begin{tabular}{|c|c|c|c|c|c|}
\hline GROUP & $\mathrm{N}$ & $\begin{array}{c}\text { Pretest } \\
\text { Mean }\end{array}$ & $\begin{array}{c}\text { Posttest } \\
\text { Mean }\end{array}$ & Mean & $\begin{array}{c}\text { Standard } \\
\text { Deviation }\end{array}$ \\
\hline $\begin{array}{c}\text { CONTROL GROUP } \\
\text { (Traditional Learning Approach) }\end{array}$ & 33 & 4.727 & 12.363 & 7.9091 & 4.51638 \\
\hline $\begin{array}{c}\text { EXPERIMENTAL GROUP } \\
\text { (Cooperative Learning Approach) }\end{array}$ & 33 & 6.091 & 12.242 & 15.1515 & 10.44665 \\
\hline
\end{tabular}

Table 4 shows the group statistics of the pretest-posttest mean gain scores in the CUT of the two groups. The table reveals that the experimental group obtained by the control group. One may also infer that the students in the experimental group gave more varied answers to the questions as shown in the large value of standard deviation.

Table 5

t-Test Result of the Pretest-Posttest Mean Gain Scores in the Conceptual Understanding Test (CUT) of the Two Groups

\begin{tabular}{|c|c|c|c|c|}
\hline GROUP & $\mathrm{N}$ & Mean Score & t-value & 2-Tail Sig \\
\hline $\begin{array}{c}\text { CONTROL GROUP } \\
\text { (Traditional Learning Approach) }\end{array}$ & 33 & 7.9091 & -3.656 & $0.001(\mathrm{~s})$ \\
\hline $\begin{array}{c}\text { EXPERIMENTAL GROUP } \\
\text { (Cooperative Learning Approach) }\end{array}$ & 33 & 15.1515 & & \\
\hline
\end{tabular}

$$
K=12 ; 48
$$

Table 5 shows that the t-value is -3.656 and the p-value is 0.001 , which is less than 0.05 level of significance. This indicates that the mean gain score of the experimental group is significantly higher than that of the control group. This also means that the students exposed to cooperative learning approach have a better conceptual understanding as compared to the control group who were taught using traditional teaching approach. It may be inferred that they have absorbed or understood the concepts and principles better within the problems than those students in the control group. Since the experimental group learned the concepts in a cooperative learning environment, probably, the group members' interaction with each other, discussing the lesson or activity with one another also contributed to better conceptual understanding.

The use of cooperative learning as an approach in teaching is one way to improve the level of conceptual understanding of the non-science curriculum high school students. Perhaps, even if the exposure of the students to cooperative learning was short, the findings of the t-test support the previous studies (Meltzer, 2002; Slavin, 1990; 
and Kagan(2002) which claimed that exposures of students to cooperative environment atmosphere significantly improved the performance and concept understanding.

Cooperative learning approach allows the students to communicate with, to share ideas and even give comments or needs to grasps the topic of concern to their cooperative group members. Knowing that each member's performance during the assessment period affect the members of their group, each student was forced to study with their group, then with themselves until they were finally confident that they could answer independently when the teacher calls. This method creates a positive atmosphere for all students. Students participation for the below average students or low achievers increased when cooperative learning was used. They were more confident and more likely to ask questions to their peers. This strategy helps the students promote better conceptual understanding.

This may explain why the mean score in the conceptual understanding test (CUT) of the experimental group has a higher increase than that of the control group. Moreover, Spencer and Miguel Kagan (1998) pointed out that the development of communication skills among students fosters the development of intelligences partly because it enhances communication of information, partly because in the process of communicating information, students sharpen their understanding. As our ideas bump into the ideas of others, and as we communicate different information or a different point of view, we are forced to rethink and develop our conceptual framework. This is one of the reasons why cooperative learning is so powerful and consistently produces gains in higher-level thinking. Interaction produces thinking, thus improving conceptual understanding

Early on, it was hypothesized that the mean gain scores obtained by the experimental and the control groups are nor significantly different. Based on the t-test result then, the hypothesis which states that: there is no significant difference between the pretest-posttest mean gain scores of the experimental and control groups has been rejected at $\mathrm{p}=0.05$.

\section{Student's Interest in Kinematics}

\section{A. Before the intervention}

The student's answers on the Student's Interest in Kinematics Questionnaire in the pre-intervention were evaluated, the results of which were earlier presented in Table 3. It is to be recalled that the two groups were not initially comparable in terms of interest in Kinematics before the intervention. The control group obtained a significantly higher mean score in the scaled responses than the experimental group. It may mean that the students in the control group may have been more interested in the lessons prior to the intervention than those in the experimental group, although their manifestation of interest was not translated into their conceptual understanding abilities.

\section{B. After the intervention}

Analysis of the students' answers on the Student's Interest in Kinematics Scale after the intervention showed that more than one half, $60.6 \%$ of the non-science curriculum high school students perceived to be undecided in many statements, shows interest in physics particularly on Kinematics.

Table 6

The Percentage Distribution of the Post Intervention Scaled Responses on the Interest of Students in Kinematics from the Two Groups

\begin{tabular}{|c|c|c|c|c|c|}
\hline \multirow{2}{*}{ Group } & \multirow{2}{*}{ Count } & \multicolumn{3}{|c|}{ Student's Interest in Kinematics } & \multirow{2}{*}{ Total } \\
\cline { 3 - 5 } & & partly & undecided & sometimes & \\
\hline Control Group & $\%$ within group & 1 & 16 & 16 & 33 \\
& & $3.0 \%$ & $48.5 \%$ & $48.5 \%$ & $100.0 \%$ \\
\hline Experimental & $\%$ within group & 0 & 24 & 9 & 33 \\
Group & & $0.0 \%$ & $72.7 \%$ & $27.3 \%$ & $100.0 \%$ \\
\hline Total & 1 & 40 & 25 & 66 \\
& & $1.5 \%$ & $60.0 \%$ & $37.9 \%$ & $100.0 \%$ \\
\hline
\end{tabular}

(C) 2019, IJSMS 
As revealed in Table 6, a greater percentage of students in the experimental group were undecided in their perception as to whether they agree or not on the statements in the interest scale. Lower percentage of the respondents answered "partly" and "sometimes" responses on whether they like or dislike Kinematics in the experimental group than in the control group. The "undecided" responses of the students may be due to the pressure or the demands of time put on them as they experienced learning the concepts through cooperative approach. It is to be recalled that they were told earlier that the performance rating of the group depend on each member, hence their interest as they perceive reflected in their choice of "undecided" response.

Moreover, more than one-forth, $37.9 \%$ of the respondents sometimes agreed that they were interested in Kinematics and that sometimes the subject physics did not frighten them, For these students, perhaps they may have felt interested in facing the challenges brought about by their being exposed to problem solving activities. Two students shared their feeling about their $\mathrm{d}=$ being challenged during the interview.

The Pre-Post intervention mean gain scores of the two groups of respondents on the Interest in Kinematics Scale are presented in Table 7.

Table 7

Pre-Post Intervention Mean Gain Scaled Responses on the Student's Interest in Kinematics Questionnaire of the Two Groups

\begin{tabular}{|c|c|c|c|}
\hline GROUP & No. of cases & Mean & $\begin{array}{c}\text { Standard } \\
\text { Deviation }\end{array}$ \\
\hline $\begin{array}{c}\text { CONTROL GROUP } \\
\text { (Traditional Learning Approach) }\end{array}$ & 33 & 3.3334 & 0.29758 \\
\hline $\begin{array}{c}\text { EXPERIMENTAL GROUP } \\
\text { (Cooperative Learning Approach) }\end{array}$ & 33 & 3.1299 & 0.29960 \\
\hline
\end{tabular}

The table reveals that the control group posted a higher mean on the scaled responses than the experimental group on the interest in Kinematics. The same pattern has been manifested by the control group during the preintervention phase of this study. This indicates that the control group were able to sustain their interest in the topics discussed or taught from the start to the end of the intervention.

Table 8

t-Test Result of the Pre-Post Intervention Mean Gain Scores the Student's Interest in Kinematics Scaled Responses of the Two Groups

\begin{tabular}{|c|c|c|c|c|}
\hline GROUP & No. of cases & $\begin{array}{c}\text { Mean } \\
\text { response }\end{array}$ & t-value & 2-Tail Sig \\
\hline $\begin{array}{c}\text { CONTROL GROUP } \\
\text { (Traditional Learning Approach) }\end{array}$ & 33 & 3.3334 & 2.768 & $0.007(\mathrm{~s})$ \\
\hline $\begin{array}{c}\text { EXPERIMENTAL GROUP } \\
\text { (Cooperative Learning Approach) }\end{array}$ & 33 & 3.1299 & & \\
\hline
\end{tabular}

$\mathrm{s}=$ significant

Table 8 shows the t-test result obtained from the comparison of the two group's interest in Kinematics. The $t$-value is 2.768 and the $p$-value $=0.007$ is less than 0.05 level of significance. This indicates that the mean gain score of the scaled responses of the Control Group is significantly higher than that of the Experimental Group. The result showed that the students exposed to Traditional Learning Approach manifested greater interest in Kinematics than those exposed to Cooperative Learning Approach. It is to be noted that the mean responses of the experimental group is lower than that of the control group. Cooperative Learning Approach to the students does not necessarily mean increase in the interest of students in Kinematics. This result is almost the same with the study of Deavor (2000) on investigating cooperative learning on the analytical chemistry class. Deavor found out that although students and faculty alike were enthusiastic about the experience, they both learned to appreciate the team work approach to learning. The goals of decreasing boredom and introducing the team work approach were achieved. Students found the team work approach to be less stressful. They were able to confer with their peers in order to 
accomplish their tasks and learned how to accept responsibility but cooperative learning has not necessarily increased the student's interest.

Students under Traditional Learning Approach posted a higher mean gain score in the Interest Scale in Kinematics probably because during the intervention, most of the discussion and imparting of ideas were done by the teacher inasmuch as they are already used to the teaching method as passive learners. Students are not frightened whether they will be called by the teacher or will be forced to share knowledge to the class. This result is supported by the study of Yesilyurt (2003) on investigating student's interest and attitudes about basic physics class. The researcher found out that the interest levels of the control and experimental groups from the first and second questionnaire were the same. After the constructivist model was applied to the experimental group, it was found that there was no significant difference among the interest levels of groups.

Students' Interest in Kinematics Prior and Post to Intervention within Groups

Table 9

t-Test Result of the Pre-Post Intervention Mean Gain Scaled Responses on the Student's Interest in Kinematics Questionnaire within the Control Group

\begin{tabular}{|c|c|c|c|c|c|}
\hline & & No. of cases & Mean response & t-value & 2-Tail Sig \\
\hline \multirow{2}{*}{ Control Group } & Pre-intervention & 33 & 3.3334 & \multirow{2}{*}{1.689} & $0.101(\mathrm{~ns})$ \\
\cline { 2 - 6 } & Post-intervention & 33 & 3.4286 & & \\
\hline \multirow{2}{*}{ Experimental Group } & Pre-intervention & 33 & 3.129 & 6.680 & $0.000(\mathrm{~s})$ \\
\cline { 2 - 7 } & Post-intervention & 33 & 3.403 & & \\
\hline
\end{tabular}

$\mathrm{ns}=$ not significant

Table 9 presents the t-test result of the Pre-Post Intervention Mean Gain Scaled Responses on the Student's Interest in Kinematics Questionnaire within the control group. It can be seen that the $t$-value is 1.689 and the $p$-value is 0.101 . This means that the pre-intervention scaled responses of the control group did not significantly differ from their post-intervention scaled responses. The pre-intervention scaled responses and the post-intervention scaled responses of the control group were almost the same or their perceptions of interest did not change after the intervention. Although they may manifest greater interest towards Kinematics than those in the experimental group as shown in Table 8 and 9, the mean gain score they obtained from the pre-post intervention was not significant. One might presume that their interest which they have shown at the start of the intervention has been due to the challenge that they have put upon themselves knowing that they were taught the traditional way. Perhaps too, there was not much motivation from the teacher for them to become more interested.

In the t-test result of the Pre-Post Intervention Mean Gain Scaled Responses on the Student's Interest in Kinematics Questionnaire within the experimental group reveals that the $t$-value is 6.689 and the $p$-value is 0.000 which is significant at $\alpha=0.05$. This indicates that the mean score of the pre-intervention scaled responses of the experimental group differs from the mean score they obtained in their post-intervention scaled responses. The mean gain scaled responses of the experimental group in the post intervention is significantly higher than in the preintervention. It was found out that the student's interest in Kinematics improved after the intervention. This implies that students under the experimental group may have been motivated to learn towards the end of the intervention as compared to their lukewarm behaviour at the beginning of the intervention. The lukewarm interest manifested by the group at the beginning of the intervention may be due to their apprehension that they will be doing the assigned task by primarily by themselves. As they did the lessons and the tasks daily, it seems that they were able to shift from a passive to an active learner and became more interested to do the daily tasks and lessons. One may surmise that, because of their interaction with their group mates, where there were exchanges of ideas or views about the lessons at hand, they became more interested in the topics thus their responses improved.

\section{CONCLUSION}

The research, replicated in this study that the Cooperative Learning Approach to teaching Kinematics can improve the conceptual understanding of the senior non-science high school students but not significantly on increasing the interest of the students in learning Kinematics. Moreover, Erlis and Subramniam (2004) pointed out based on their study that the use of cooperative learning fosters conceptual understanding and can be used as a vehicle to promote 
International Journal of Science and Management Studies (IJSMS)

Volume: 2 Issue: 3
May to June 2019
E-ISSN: 2581-5946

www.ijsmsjournal.org

thinking skills among students. It also provides an opportunity for peer interaction. Furthermore, in the study of Buan (1997) she found out that the mean gain scores in both achievement test and attitude scale were significantly higher in the cooperative learning group than the mean gain scores of the individualistic group. This is an indication that cooperative learning instruction is better than individualistic learning. Hence high school physics teachers are encouraged to explore and apply strategies of teaching like cooperative learning that can enhance the conceptual understanding of the students.

\section{References:}

[1] Biggs, J B \& Collis, K F (1982).“Evaluating the quality of learning THE SOLO TAXONOMY.”Australia: Academic Press

[2] Brown, G. T. L. (2002) "Student Beliefs About Learning”. Academic Exchange Quarterly, 11-14

[3] Cagas, Bartolome L. (1998). "Concept-Oriented Problem-Solving Approach: Effects on High School Students' Performance and Conceptual Understanding in Physics". M.A.E., Masteral Thesis, College of Education, University of the Philippines, Diliman, Quezon City.

[4] Erlis, M. \&Subramaniam, R. (2004).“Use of Cooperative Learning to Foster Conceptual Understanding in Chemistry among Students.National Institute of Education, Nanyang Technological University, Nanyang Walk, Singapore.

[5] Gericke, N. M et al (2015): The Effectiveness of education for Sustainable Development.Sustainability 2015(7):15693-15717. DOI:10.3390/SU71115693

[6] Gericke.D H (1996).“Assessing transformative learning: the SOLO taxonomy”.Unpublished paper.

[7] Johnson, D.W., and Johnson, R.T. (2001).Cooperative Learning in the Classroom. Alexandria, VA: Association for Supervision and Curriculum.

[8] Kagan, S. \&Kagan M. (2009) Kagan Cooperative Learning. San Clemente, CA: Kagan Publishing.

[9] Kagan, S. (2001): Kagan Structuresare Brain Based. Kagan Online Magazine, Winter 2001

[10] Lundgren, Linda (1994). Cooperative Learning in the Science Classroom.5-11. Glencoe Division of Macmillan/McGraw-Hill.

[11] Mallory, J. L. (2004). “Factors Which Determine Interest or Fear in Physics.”Research Paper, College of William and Mary, Williamsburg, Virginia.

[12] Mazur, E. et.al (2015): Making sense of confusion: Relating performance, confidence, and self-efficacy to expressions of confusion in an introductory physics class. Physical Review Special Topics - Physical Education Research.11.DOI:10.1103/PhysRevSTPER.11.010107

[13] Meltzer, David E. (2002). "The relationship between mathematics preparation and conceptual learning gains in Physics: A possible "hidden variable" in diagnostic pretest scores". American Journal of Physics. 16, 500-111

[14] Mulhall, P. McKittrick, B. \&Gunstone (2001): A Perspective on the Resolution of Confusions in the Teaching of Electricity. Reasearch in Science education. Volume 31, Issue 4, pp 575-587

[15] Slavin, R.E. (2011).Instruction Based on Cooperative Learning. In R. E. Mayer \& P. A. Alexander (Eds), Handbook of Research on Learning and Instruction (pp 344-360). New Yorl: Taylor and Francis.

[16] Thompson, J., \&Soyibo, K. (2002).Effects of lecture, teacher demonstrations, discussion and practical work on $10^{\text {th }}$ grader's attitudes to chemistry and understanding of electrolysis". Research in Science \& Technological Education.20(1),25-35.

[17] Yesilyurt, M. (2003).A Constructivist Approach to Basic Physics Learning Applications. Unpublished Ph.D. Thesis, KTU, Trabzon.

[18] Zafran, L. (2002). "Cooperative Learning in the Secondary Mathematics Classroom: Discussion, Theory, and Contemporary Research". Research Paper, Education 05000A, College of the City University of New York. 